\title{
Antioxidant Capacity of Lenses with Age-Related Cataract
}

\author{
Bojana Kisic, ${ }^{1}$ Dijana Miric, ${ }^{1}$ Lepsa Zoric, ${ }^{2}$ Aleksandra Ilic, ${ }^{3}$ and Ilija Dragojevic ${ }^{1}$ \\ ${ }^{1}$ Institute of Biochemistry, Faculty of Medicine, 38220 Kosovska Mitrovica, Serbia \\ ${ }^{2}$ Clinic for Eye Diseases, Faculty of Medicine, 38220 Kosovska Mitrovica, Serbia \\ ${ }^{3}$ Institute of Preventive Medicine, Faculty of Medicine, 38220 Kosovska Mitrovica, Serbia \\ Correspondence should be addressed to Bojana Kisic, bojanabk2002@yahoo.com
}

Received 28 August 2012; Accepted 13 October 2011

Academic Editor: Francisco Javier Romero

Copyright (C) 2012 Bojana Kisic et al. This is an open access article distributed under the Creative Commons Attribution License, which permits unrestricted use, distribution, and reproduction in any medium, provided the original work is properly cited.

The immediate cause of the occurrence of cataract is unknown, but oxidative damage and effects of reactive oxygen species are considered important in its etiopathogenesis. Our research was aimed at testing the nonenzyme antioxidant power of corticonuclear lens blocks, with different types and different maturity of age-related cataract. Clinical and biochemical researches were carried out in 101 patients with age-related cataract. In corticonuclear lens blocks of the patient, the concentration of nonprotein and total-SH groups and the concentration of total vitamin $\mathrm{C}$ and dehydroascorbic acid (DHA) were determined; the current redox balance of dehydroascorbate/ascorbate and total antioxidant power measured by ferric-reducing ability were examined. In corticonuclear lens blocks with incipient cataract a significantly higher concentration of GSH, total SH groups, concentration of total vitamin $\mathrm{C}$ and ascorbic acid (AA), and ferric-reducing ability were measured. The measured concentration of DHA is higher than the concentration of AA in the lenses with the incipient and mature cataract. The concentration ratio of redox couple DHA/AA is higher in lenses with mature cataract, where the measured concentration of AA was lower than in the incipient cataract. Timely removal of DHA from the lens is important because of its potential toxicity as an oxidant. An increase of the current concentration of DHA/AA redox balance can be an indicator of oxidative stress.

\section{Introduction}

Oxidative stress has been implicated in the etiology of a large number of human long-term degenerative diseases including cataract. The free radicals that damage cellular macromolecules, producing oxidative stress, are scavenged in the human body by a range of antioxidant enzymes and small-molecule antioxidants. The balance between the production and catabolism of oxidants by cells and tissue is essential for the maintenance of the biologic integrity of the tissue. Ocular tissues contain antioxidants that prevent damage from excessive oxygen metabolites: antioxidant enzymes, proteins, ascorbic acid, glutathione, amino acids (cysteine and tyrosine), uric acid, and others. The fact that the incidence of cataract is higher in the population that is more exposed to sunlight $[1,2]$ imposes the assumption that photocatalytic conversion of molecular oxygen from ground state to excited states, which are highly reactive (superoxide anion $\left(\mathrm{O}_{2}^{\bullet^{-}}\right)$, hydrogen peroxide $\left(\mathrm{H}_{2} \mathrm{O}_{2}\right)$, hydroxyl radical $\left(\mathrm{OH}^{\bullet}\right)$, and others), occurs. However, despite the possibility of continuous production of these reactive molecular species in the aqueous humour and lens due to the continuous penetration of sunlight during the visual process, a latent period of development of cataract is long. The role of ascorbate is important, as an effective scavenger of hydroxyl and superoxide anion radical. High concentration of ascorbate in the aqueous humour is assumed to represent a kind of filter that prevents the penetration of UV light in the lens and thus protects tissue from oxidative damage, particularly photo-induced damage [3]. Diurnal animals have the highest concentrations, with the ascorbic acid concentration in some ocular tissues being 20-70 times higher than in plasma. Maintenance of high concentrations of vitamin $\mathrm{C}$ in the ocular structures is carried out by active transport from plasma through the barrier blood-aqueous humour. It is assumed that vitamin $\mathrm{C}$ is transported into the aqueous humour in an oxidized form as dehydroascorbic acid and then converted to a reduced form, by the effect of dehydroascorbate reductase in the presence of reduced glutathione (GSH) mainly in the lens. Since epithelial cells 
of the ciliary body contain $\mathrm{NADPH}+\mathrm{H}^{+}$and GSH, which are necessary for the reduction of dehydroascorbate, it is believed that the conversion of dehydroascorbate to ascorbate is also done during the transport. This reduction of DHA to less diffusible AA contributes to "retention" of ascorbate in the lens. Vitamin $\mathrm{C}$ in the ocular structures functions through ascorbate-dehydroascorbate redox system, which contributes to maintenance of reduced forms of pyridine nucleotides and maintenance of reduced glutathione. In the lens, the ascorbic acid prevents cation pumps damage induced by UV radiation and reduces photoperoxidation in the membranes [4].

Tripeptide glutathione is present in high concentration in the lens, mainly in reduced form (GSH) [5]. Glutathione with ascorbic acid in the lens has many functions: it protects thiol groups of lens proteins against oxidation agents, it is necessary for the function of glutathione-peroxidase (which neutralizes reactive oxygen species), it is involved in detoxification of hydrophobic substances in reactions catalysed by glutathione S-transferase enzymes. Proteins containing thiol groups are important for normal function of the lens epithelium, that is, enzyme Na-K-ATP-ase, which affect cell permeability. Lens membrane is impermeable for GSH, but it is permeable to its oxidized form (GSSG), which has consequently low concentration in the lens. Reduced glutathione, glutathione peroxidase $(\mathrm{GPx})$, glutathione reductase $(\mathrm{GR})$, and $\mathrm{NADPH}^{+}+\mathrm{H}^{+}$form antioxidant system of glutathione, in which GR and $\mathrm{NADPH}^{+}+\mathrm{H}^{+}$are necessary for reduction of oxidized glutathione and GSH regeneration. Ratio of GSH/GSSG is normally high in the lens thanks to the glutathione redox cycle, which is localized in the lens epithelium and superficial cortex [6].

Aim. Testing of nonenzyme antioxidant power of corticonuclear lens blocks, with different types and varying maturity degrees of age-related cataract, by determining the concentration of nonprotein and total SH groups, concentration of total vitamin $\mathrm{C}$ and dehydroascorbic acid and examining the actual redox couple dehydroascorbate/ascorbate, and total antioxidant power of the lens by measuring its ferric reducing ability.

\section{Material and Methods}

Lens-Reduced Glutathione (GSH) Assay. To determine lens GSH, $0.2 \mathrm{~mL}$ of the sample was added directly into tubes containing $0.2 \mathrm{~mL}$ of $1 \mathrm{~mol} / \mathrm{L}$ perchloric acid supplemented with $2 \mathrm{mmol} / \mathrm{L}$ of disodium EDTA, vortex-mixed, and centrifuged for $5 \mathrm{~min}$ at $10000 \mathrm{~g}\left(4^{\circ} \mathrm{C}\right)$ to remove the protein precipitate. Lens GSH was determined in a clear supernatant using Ellman's reagent [7]. $0.2 \mathrm{~mL}$ of this supernatant, $0.8 \mathrm{~mL}$ of $0.3 \mathrm{mmol} / \mathrm{L} \mathrm{Na}_{2} \mathrm{HPO}_{4}$, and $0.2 \mathrm{~mL}$ of $5,5^{\prime}$-dithiobis2nitrobenzoic acid in $1 \%$ sodium citrate were added in succession. The intensity of the resulting yellow colour was read spectrophotometrically at $410 \mathrm{~nm}$.

Lens Total Sulfhydryl Groups (TSH) Assay. Lens total sulfhydryl groups (TSH) were determined using Ellman's reagent without prior deproteinization [8].
Total Vitamin C (Ascorbic Acid and Dehydroascorbic Acid) Assay. The concentration of total vitamin $\mathrm{C}$ was determined by using the method of 2,4-dinitrophenylhydrazine [9], which in acidic environment builds up coloured bis2,4-dinitrophenylhydrazine of ascorbic acid. This method determines the concentration of total vitamin $\mathrm{C}$, in the form of ascorbate and dehydroascorbate, and then in coloured reaction at the same time it determines the existing and subsequently formed dehydroascorbate. Protein samples are removed by adding a fourfold volume of $0.61 \mathrm{~mol} / \mathrm{L}$ trichloroacetic acid, and coloured reaction is performed with $1.2 \mathrm{~mL}$ of the supernatant in the presence of $0.4 \mathrm{~mL}$ DTBS reagent $(32.85 \mathrm{mmol} / \mathrm{L}$ thiourea, $1.88 \mathrm{mmol} / \mathrm{L}$ copper sulphate, $90 \mathrm{mmol} / \mathrm{L}$ 2,4-dinitrophenylhydrazine, and $4.5 \mathrm{~mol} / \mathrm{L}$ sulphuric acid). After incubation for 180 minutes at $37^{\circ} \mathrm{C}$, the samples are cooled for 10 minutes on ice, $2 \mathrm{~mL}$ of $12 \mathrm{~mol} / \mathrm{L}$ sulphuric acid is added to each of them, and absorbance of coloured product is read at $\lambda=520 \mathrm{~nm}$ against a reagent blank, which contains trichloroacetic acid instead of supernatant sample. In the same way standards of vitamin $\mathrm{C}$ were analyzed (freshly prepared aqueous solutions of ascorbic acid concentration of $180-240 \mu \mathrm{mol} / \mathrm{L}$ ).

Dehydroascorbic Acid (DHA) Assay. Dehydroascorbic acid concentration in the sample was determined by the same method, with the omission of copper sulphate solution in DTBS reagent, and the ascorbate (AA) concentration was calculated from the difference between total vitamin $\mathrm{C}$ and DHA.

The Ferric Reducing Ability of Lens (FRAL) Assay. The ferric reducing ability of lens (FRAL) assay was used for determination of antioxidant power in lens: at low $\mathrm{pH}$, when a ferric tripyridyltriazine $\left(\mathrm{Fe}^{+3}-\mathrm{TPTZ}\right)$ complex is reduced to the ferrous $\left(\mathrm{Fe}^{+2}\right.$-TPTZ) form, an intense blue color with an absorption maximum at $593 \mathrm{~nm}$ develops [10]. Reagent Preparation. Reagents included $300 \mathrm{mmol} / \mathrm{L}$ acetate buffer, $\mathrm{pH}$ 3.6; $10 \mathrm{mmol} / \mathrm{L}$ TPTZ (2,4,6-tripyridyl-s-triazine) in $40 \mathrm{mmol} / \mathrm{L} \mathrm{HCL} ; 20 \mathrm{mmol} / \mathrm{L} \mathrm{FeCl} 3 \cdot 6 \mathrm{H}_{2} \mathrm{O}$. Working FRAL reagent was prepared as required by mixing $25 \mathrm{~mL}$ acetate buffer, $2.5 \mathrm{~mL}$ TPTZ solution, and $2.5 \mathrm{~mL} \mathrm{FeCl}{ }_{3} \cdot 6 \mathrm{H}_{2} \mathrm{O}$ solution. Aqueous solutions of known Fe (II) concentration, in the range of $100-1000 \mu \mathrm{mol} / \mathrm{L}\left(\mathrm{FeSO}_{4} \cdot 7 \mathrm{H}_{2} \mathrm{O}\right)$, were used for calibration.

2.1. Patients. Clinical and biochemical researches were carried out in 101 patients with age-related cataract (ARC), 46 women and 55 men. The average age of the group was 72.5 $(\mathrm{SD} \pm 7.98)$. According to the cataract maturity degree, the patients were classified into two groups: age-related cataract incipiens $(N=41)$ and matura $(N=60)$.

Samples of lens corticonuclear blocks were obtained from patients undergoing extracapsular extraction of agerelated cataracts and used as the test material. Types of cataract were estimated during ophthalmologic examination and confirmed during its extraction.

Immediately after sample acquisition, samples were closed in individual capsules and deeply frozen. This research 
TABLE 1: Nonenzymatic antioxidative defense factors in cataractous lenses.

\begin{tabular}{lcc}
\hline & $\begin{array}{c}\text { Age-related } \\
\text { cataract incipiens } \\
(n=41)\end{array}$ & $\begin{array}{c}\text { Age-related } \\
\text { cataract matura } \\
(n=60)\end{array}$ \\
\hline $\mathrm{GSH}(\mu \mathrm{mol} / \mathrm{g}$ lens $)$ & $2.6 \pm 0.9$ & $0.9 \pm 0.3^{*}$ \\
$\mathrm{TSH}(\mu \mathrm{mol} / \mathrm{g}$ lens $)$ & $102.5 \pm 25.5$ & $54.8 \pm 19.7^{*}$ \\
$\mathrm{Total}$ vitamin C & $0.61 \pm 0.19$ & $0.46 \pm 0.16^{*}$ \\
$(\mu \mathrm{mol} / \mathrm{mg}$ lens $)$ & $0.19 \pm 0.07$ & $0.11 \pm 0.04^{*}$ \\
$\mathrm{AA}(\mu \mathrm{mol} / \mathrm{mg}$ lens $)$ & $0.41 \pm 0.13$ & $0.38 \pm 0.13$ \\
$\mathrm{DHA}(\mu \mathrm{mol} / \mathrm{mg}$ lens $)$ & $2.3 \pm 0.6$ & $3.4 \pm 0.7^{*}$ \\
$\mathrm{D} / \mathrm{A}$ & $4.0 \pm 1.3$ & $1.4 \pm 0.4^{*}$ \\
$\mathrm{FRAL}(\mu \mathrm{mol} / \mathrm{g}$ lens $)$ &
\end{tabular}

Data is presented as means $\pm \mathrm{SD} * P<0.001$. GSH-Glutathione reduced TSH-Total-SH group AA-Ascorbic acid DHA-dehydroascorbic acid D/A—Dehydroascorbic acid/ascorbic acid FRAL—Ferric-reducing ability of lens.

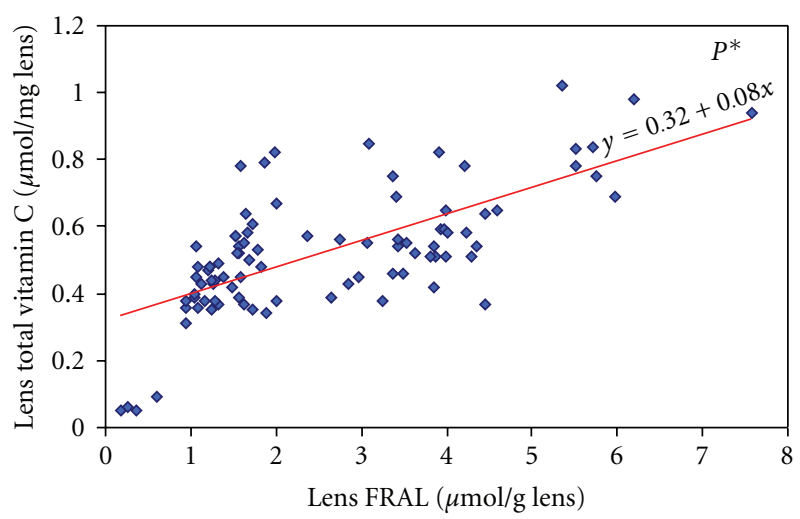

FIgure 1: Lens total vitamin C and FRAL relationship in age-related cataract.

has been conducted following the tenets of the Declaration of Helsinki and approved by the ethics committee of Medical Faculty. Informed consent was provided from all patients after a careful explanation of the aims of the study.

Sample Collection and Preparation. The wet weight of the lens corticonuclear blocks was recorded (gr). The lenses corticonuclear blocks from each group were homogenized in 10 times their mass of cold $0.2 \mathrm{~mol}$ potassium phosphate buffer ( $\mathrm{pH} 7.2$ ) supplemented with $137 \mathrm{mmol} / \mathrm{L} \mathrm{KCl}$ and $60 \mathrm{mmol} / \mathrm{L}$ sodium dodecyl sulfate. The water-insoluble material was removed by centrifuging for 20 minutes at $12000 \mathrm{~g}\left(4^{\circ} \mathrm{C}\right)$.

2.2. Statistical Analysis. Values were expressed as means \pm $\mathrm{SD}$. A comparison between groups was performed by Student's $t$-test and Mann-Whitney $U$-test. Correlation analysis was accomplished via calculation of Pearson's coefficient.

\section{Results}

By analyzing measured concentrations, significantly higher concentrations of GSH $(P<0.001)$ and total SH groups $(P<0.001)$ were found as well as significantly higher ferric

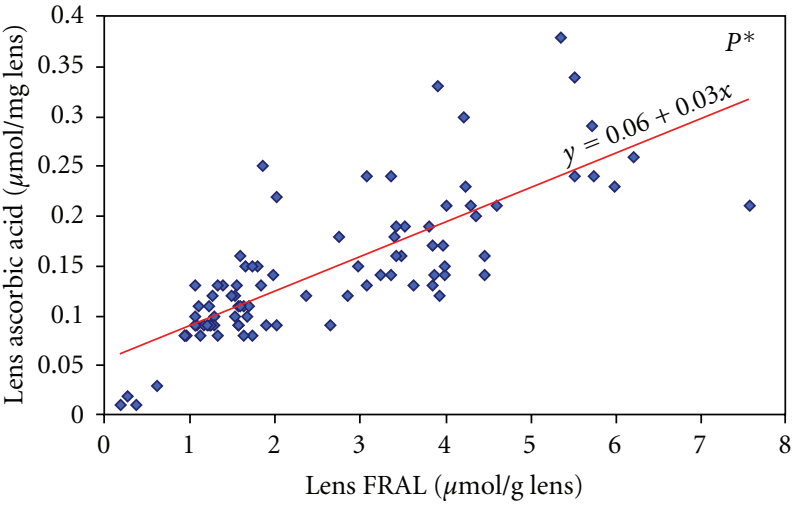

FIGURE 2: Lens ascorbic acid and FRAL relationship in age-related cataract.

reducing ability $(P<0.001)$ in corticonuclear lens blocks with incipient cataract (Table 1).

Average measured concentrations of total vitamin C and dehydroascorbate in homogenate of cataract lenses are shown in the Table 1. Testing the difference, depending on the maturity degree of the cataract, a significantly higher concentration of total vitamin $\mathrm{C}(P<0.001)$ was found in the lenses with the incipient cataract. Measured concentrations of dehydroascorbate in lenses do not differ depending on the maturity degree of cataract $(P=0.250)$. The concentration of ascorbate obtained from the difference between the total concentration of vitamin $\mathrm{C}$ and dehydroascorbate is significantly higher in lenses with incipient cataract $(P<$ 0.001 ). In order to assess participation of vitamin $C$ in antioxidant protection of the lens, the concentration ratio of dehydroascorbate/ascorbate (DHA/AA) was determined, and significantly higher values of DHA/AA ratio $(P<0.001)$ were found in lenses with mature cataract (Table 1). By examining the relation between the concentration of total vitamin $\mathrm{C}$ and ferric reducing ability of the lens, we found a significant positive correlation $(r=0.683, P<0.001)$ (Figure 1) between the concentration of ascorbate (AA) and ferric-reducing ability of the lens $(r=0.780, P<0.001)$ (Figure 2), between the concentration of GSH and ferricreducing ability of the lens $(r=0.804, P<0.001)$ (Figure 3 ), and between the total $\mathrm{SH}$ groups and ferric-reducing ability of the lens $(r=0.726, P<0.001)$ (Figure 4$)$.

Multiple regression analysis examined the participation of certain antioxidants in the total antioxidant activity lens (FRAL) with age-related cataract. The model includes biochemical parameters of GSH, T-SH, AA, DHA, and D/A, which explained $82.1 \%$ variance values FRAL tested multiple regression analysis. Significant unique contribution to prediction of FRAL gives ascorbate (AA) $(\beta=0.358$, $P<0.01)$ and GSH $(\beta=0.484, P<0.001)$, (Table 4$)$.

By analyzing the relation between concentrations of total vitamin $\mathrm{C}$ and GSH, significant positive correlation $(r=$ $0.410, P<0.001$ ) was determined (Figure 5), as well as between concentrations of ascorbic acid (AA) and TSH groups in the lens $(r=0.542, P<0.001)$ (Figure 6).

The concentration of nonprotein and total SH groups in corticonuclear lens blocks with different types of incipient 


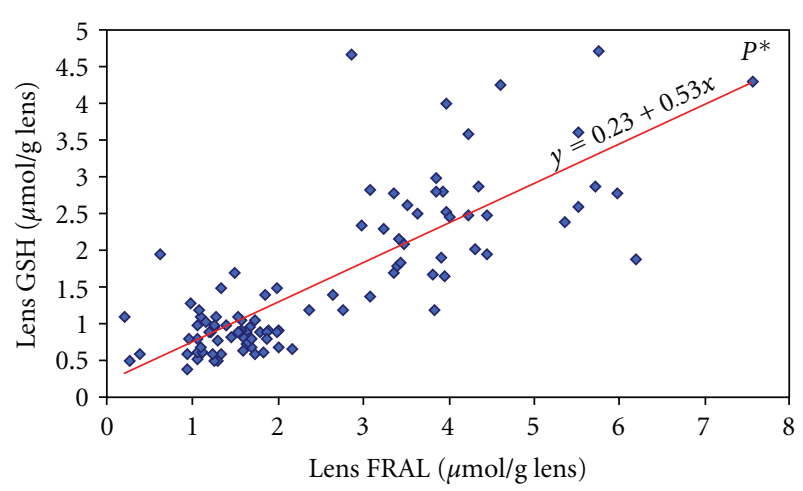

FIGURE 3: Lens GSH and FRAL relationship in age-related cataract.

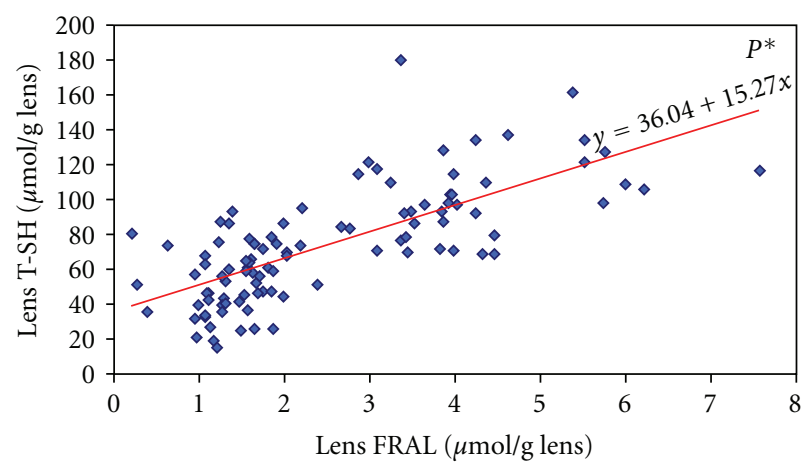

FIGURE 4: Lens T-SH and FRAL relationship in age-related cataract.

TABle 2: Nonenzymatic antioxidative defense factors in lenses with cataract incipiens.

\begin{tabular}{lccc}
\hline $\begin{array}{l}\text { Cataract incipiens } \\
\text { (type })\end{array}$ & $\begin{array}{c}\text { PS } \\
(n=23)\end{array}$ & $\begin{array}{c}\text { NP } \\
(n=9)\end{array}$ & $\begin{array}{c}\text { CN } \\
(n=9)\end{array}$ \\
\hline GSH $(\mu \mathrm{mol} / \mathrm{g}$ lens $)$ & $3.0 \pm 0.9$ & $2.2 \pm 0.6^{*}$ & $1.8 \pm 0.4^{* *}$ \\
TSH $(\mu \mathrm{mol} / \mathrm{g}$ lens $)$ & $114.2 \pm 26.3$ & $89.2 \pm 18.6^{*}$ & $85.8 \pm 10.8^{* *}$ \\
Total vitamin C & $0.64 \pm 0.2$ & $0.52 \pm 0.17$ & $0.61 \pm 0.15$ \\
$(\mu \mathrm{mol} / \mathrm{mg}$ lens $)$ & $0.2 \pm 0.08$ & $0.16 \pm 0.06$ & $0.09 \pm 0.19$ \\
AA $(\mu \mathrm{mol} / \mathrm{mg}$ lens $)$ & $0.44 \pm 0.14$ & $0.36 \pm 0.13$ & $0.41 \pm 0.11$ \\
DHA $(\mu \mathrm{mol} / \mathrm{mg}$ lens $)$ & $2.3 \pm 0.7$ & $2.3 \pm 0.6$ & $2.2 \pm 0.6$ \\
D/A & $4.5 \pm 1.2$ & $3.6 \pm 1.2$ & $3.4 \pm 0.5^{*}$ \\
FRAL $(\mu \mathrm{mol} / \mathrm{g}$ lens $)$ &
\end{tabular}

Data is presented as means $\pm \mathrm{SD}, * P<0.05,{ }^{* *} P<0.01$. PS-Posterior subcapsular NP-Nuclear subcapsular $\mathrm{CN}$-Cortical nuclear.

cataract is presented in Table 2. GSH and total SH groups concentration is higher in lenses with posterior subcapsular in relation to nuclear subcapsular cataract $(P<0.05)$ and in lenses with posterior subcapsular in relation to incipient corticonuclear cataract $(P<0.01)$.

Estimation of total antioxidant ability of corticonuclear lens blocks with incipient cataract was performed by FRAL analysis. Testing the difference of obtained values, a significantly higher ferric-reducing ability was found in lenses with subcapsular cataract than in lenses with corticonuclear cataract $(P<0.05)$, (Table 2).

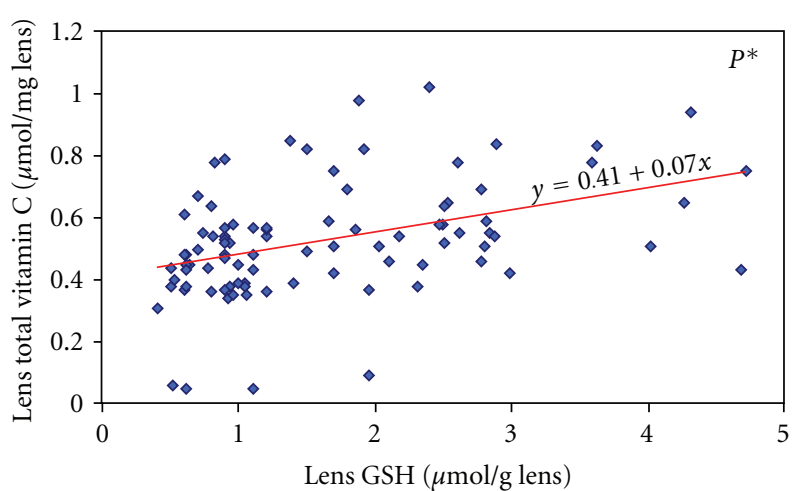

FIGURE 5: Lens GSH and total vitamin C relationship in age-related cataract.

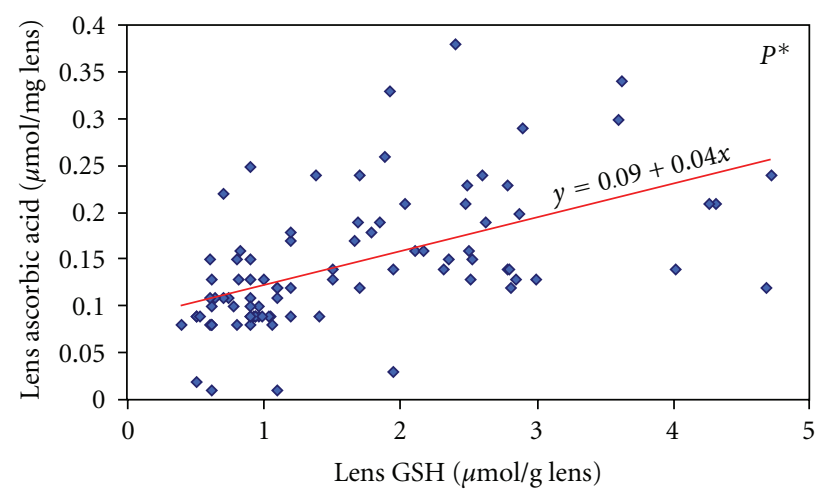

FIGURE 6: Lens GSH and ascorbic acid relationship in age-related cataract.

Since the total antioxidant activity is determined by FRAL analysis, the concentration ratio between some antioxidant protection factors and total antioxidant ability of sample in lenses with incipient cataract was examined. By examining the correlation ratio between the concentrations of total vitamin $\mathrm{C}$ and ferric-reducing ability in lenses with incipient cataract, a significant positive correlation $(r=$ $0.743, P<0.001)$ was found also between the concentration of ascorbate and values of FRAL $(r=0.621, P<0.001)$, between nonprotein thiol concentration and ferric-reducing ability of lenses $(r=0.420, P<0.01)$, and between the concentration of total SH and values of FRAL $(r=0.334$, $P<0.05)$.

Average measured concentrations of total vitamin C and dehydroascorbate in corticonuclear lens blocks with incipient cataract are presented in Table 2. The concentration of ascorbate in the same samples was calculated from the difference between concentrations of total vitamin $\mathrm{C}$ and dehydroascorbate, and in order to estimate the participation of vitamin $\mathrm{C}$ in antioxidant protection of lenses with incipient age-related cataract, the concentration ratio of dehydroascorbate/ascorbate was determined.

By analyzing the variances, it was determined that lenses with different types of incipient cataract do not differ in concentration of total vitamin $C(P=0.246)$, 
TABle 3: Nonenzymatic antioxidative defense factors in lenses with cataract matura.

\begin{tabular}{lccc}
\hline $\begin{array}{l}\text { Cataract matura } \\
\text { (type) }\end{array}$ & $\begin{array}{c}\text { Age-related cataract } \\
\text { matura began as PS } \\
(N=19)\end{array}$ & $\begin{array}{c}\text { Age-related cataract } \\
\text { matura began as NP } \\
(N=15)\end{array}$ & $\begin{array}{c}\text { Age-related cataract } \\
\text { matura began as CN } \\
(N=16)\end{array}$ \\
\hline GSH $(\mu \mathrm{mol} / \mathrm{g}$ lens $)$ & $1.0 \pm 0.2$ & $0.8 \pm 0.2$ & $0.8 \pm 0.3$ \\
TSH $(\mu \mathrm{mol} / \mathrm{g}$ lens $)$ & $59.9 \pm 16.6$ & $58.0 \pm 20.8$ & $48.2 \pm 21.9$ \\
Total vitamin C & $0.49 \pm 0.18$ & $0.43 \pm 0.19$ & $0.44 \pm 0.07$ \\
$(\mu \mathrm{mol} / \mathrm{mg}$ lens $)$ & $0.12 \pm 0.05$ & $0.1 \pm 0.04$ & $0.1 \pm 0.02$ \\
AA $(\mu \mathrm{mol} / \mathrm{mg}$ lens $)$ & $0.37 \pm 0.14$ & $0.33 \pm 0.15$ & $0.44 \pm 0.07^{*}$ \\
DHA $(\mu \mathrm{mol} / \mathrm{mg}$ lens $)$ & $3.4 \pm 0.8$ & $3.4 \pm 0.7$ & $3.5 \pm 0.6$ \\
D/A & $1.6 \pm 0.5$ & $1.4 \pm 0.5$ & $1.2 \pm 0.2^{*}$ \\
\hline
\end{tabular}

Data is presented as means $\pm \mathrm{SD}, * P<0.05$. PS—posterior subcapsular NP—nuclear subcapsular $\mathrm{CN}$-cortical nuclear.

TABLE 4: Multiple regression analysis.

\begin{tabular}{lccc}
\hline Variable & SE & $\beta$ & $P$ \\
\hline FRAL $(\mu \mathrm{mol} / \mathrm{g}$ lens $)$ & 0.153 & & \\
GSH $(\mu \mathrm{mol} / \mathrm{g}$ lens $)$ & 0.103 & 0.484 & $<0.001^{*}$ \\
TSH $(\mu \mathrm{mol} / \mathrm{g}$ lens $)$ & 3.123 & 0.107 & 0.156 \\
AA $(\mu \mathrm{mol} / \mathrm{mg}$ lens $)$ & 0.007 & 0.358 & $0.008^{*}$ \\
DHA $(\mu \mathrm{mol} / \mathrm{mg}$ & 0.014 & 0.11 & 0.272 \\
lens & 0.091 & -0.051 & 0.617 \\
D/A & & &
\end{tabular}

dehydroascorbate $(P=0.348)$, ascorbate $(P=0.267)$, and concentration ratio of DHA/AA $(P=0.955)$ (Table 2).

Average measured concentrations of nonprotein and total thiols, as well as their differences in lenses with mature age-related cataract which started in different ways, are shown in Table 3. By analyzing the variances, no significant difference in concentrations of GSH $(P=0.111)$ was found, or the difference of total thiols $(P=0.268)$ in lenses with mature age-related cataract, depending on type that cataract started with.

By testing differences of ferric reducing ability of examined lenses, a significantly higher ferric-reducing activity was found in lenses with mature cataract started as subcapsular as compared to lenses in which the cataract started as corticonuclear $(P<0.05)$ (Table 3$)$.

By examining the relation, concentration of total vitamin $\mathrm{C}$ and ferric-reducing ability of lenses with mature cataract, was found a positive correlation $(r=0.728, P<0.001)$ between the concentration of ascorbate and ferric-reducing ability of lenses $(r=0.679, P<0.001)$ and between the concentration of total thiol groups and FRAL values $(r=$ $0.296, P<0.05)$.

Average measured concentrations of total vitamin $\mathrm{C}$ and dehydroascorbate in lenses with mature cataract, and their differences among lenses in which the cataract started in different ways, are shown in Table 3. By analysing variances, no significant difference in concentration of total vitamin C $(P=0.582)$ and ascorbate $(P=0.397)$ was found, as well as ratio of DHA/AA $(P=0.913)$ in lenses with mature cataract, depending on how the cataract started. Significantly higher concentration of dehydroascorbate was measured in lenses where the cataract started as corticonuclear, compared to lenses where the cataract started as subcapsular-nuclear $(P<0.05)$, (Table 3$)$.

\section{Discussion}

Vitamin C has not only antioxidant, but also prooxidant properties. In which direction will vitamin $\mathrm{C}$ work, depends on the concentration of vitamin C, oxygen and the presence of metal ions. Oxidation is the cause of modification of lens proteins which accumulate over a lifetime [11]. These modifications lead to the formation of molecular aggregates with high molecular weight causing light scattering, which is a characteristic of cataract. Some believe that ascorbate can contribute to protein modifications, react as prooxidant, and participate in reactions that generate radicals. These reactions may be caused by light or metal-catalyzed oxidation of endogenous ascorbic acid. It is known that copper and iron are present in micromolar concentrations and that autooxidative processes can occur in the lens. In the presence of metals, especially iron and copper, and oxygen, ascorbic acid is oxidized to dehydroascorbate, which produces hydrogen peroxide, and metal is reduced. Hydrogen peroxide can react with reduced metal, generating hydroxyl radical and other reactive oxygen radicals [4]. When copper and protein-bound iron is included in this reaction, the radicals cause oxidative modification of amino acids that are near the metal. These reactions become important when cells lose their ability to remove metals, making it available for reaction, and/or when cells lose their ability to maintain their vitamin $C$ in a reduced form. It is noted that during the aging of lens, as in cataract lenses, the concentration of copper and iron increases [12]. The data that confirm the level of iron and copper ions is lower in noncataract lenses, suggesting that metal ions that mediate the production of $\mathrm{HO}^{\circ}$, may be important in the development of age-related cataract [13].

Reaction of lens proteins with ascorbic acid in vitro, in presence of metals (copper or iron), induces protein modifications that have been also observed on cataract lenses. Ascorbate forms covalent bonds with crystalline lens, which reduces the solubility of proteins $[14,15]$. This indicates 
the potential role of ascorbic acid in the lens proteins modification during the development of cataract. However, these reactions occur when factors that cause oxidative damage overcome the capacity of antioxidant mechanisms of altered metabolism of metal or when the maintenance mechanism of reduced form of ascorbic acid is compressed.

Analyzing the measured concentration of GSH in lenses of our patients with age-related cataract, significantly lower concentrations of GSH were found in lenses with mature cataract $(0.9 \pm 0.3 \mu \mathrm{mo} / \mathrm{g})(P<0.001)$ than those in lenses with incipient cataract $(2.6 \pm 0.9 \mu \mathrm{mo} / \mathrm{g})$. These results are consistent with the results of other researchers who showed that the level of reduced glutathione in the lens decreases with the development of cataract $[16,17]$, and that with cataract progression towards the mature, the activity of glutathione reductase and $\mathrm{NADPH}^{+} \mathrm{H}^{+}$-dependent enzymes of pentose-phosphate pathway is decreased. Reduction of concentration of GSH in cataract lenses occurs for several reasons, probably as a result of intense oxidation processes and formation of toxic products of lipid peroxidation [1820] on one hand, compared to a weakened antioxidant capacity of cataract lenses, on the other. As the main representative of nonprotein thiols, GSH is included and used in oxidoreduction processes in conditions of excess oxidized substrates. It is possible that during oxidative stress GSH is converted to an oxidized form, which further conjugates with thiol groups (structural and membrane) proteins, thus reducing the amount of hydrosoluble proteins in the lens and the lens turbidity [6]. Other researchers have shown that in cataract lenses significant amounts of GSH are bound with protein thiols by disulphide bridges where the mixed disulfides of protein-S-S-GSH (PSSG) type are formed [21]. The reasons that lead to the conjugation of nonprotein thiols with proteins are insufficiently known and in order to come to know them, the researchers conducted animal lens studies. Thus, exposure of rat lenses to higher concentrations of hydrogen peroxide caused a reduction of GSH concentration and an increase of the amounts of protein-S-S-GSH products. These changes were accompanied by a reduction of the concentration of hydrosoluble proteins, increase of amount of protein insoluble in water, and occurrence of lens turbidity [22].

A possible reason for an amount of reduced glutathione in the lenses of patients with age-related cataract is the lack of hexose monophosphate shunt, responsible for the synthesis of $\mathrm{NADPH}^{+}+\mathrm{H}^{+}$, which is necessary for the function of glutathione reductase [5]. Glutathione reductase (GR) reduces oxidized glutathione (GSSG) to glutathione (GSH) with electrons donated from reduced form of nicotinamideadenine dinucleotide phosphate $\left(\mathrm{NADPH}^{+}+\mathrm{H}^{+}\right)$allowing GSH to protect protein thiols from oxidative damage and prevent protein cross-link formation. Other researchers have demonstrated that lens GR activity decreases with aging and cataract formation [23]. Decrease of the GR activity may be responsible for the low levels of free GSH in the cataractous lenses. Possible causes of reduction of GR activity in the lens during the development of cataract are the chronic exposure to UVA light of the solar spectrum [24] and/or oxidative modification of enzymes by reactive oxygen radicals [25]. Linetsky and associates have suggested that chronic exposure to UVA light in the development of cataract leads to absorption of UVA light by flavin adenine dinucleotide (FAD) and coenzyme GR, which causes its photolysis and inactivation of the enzyme glutathione reductase [24]. Other authors suggest that a possible cause of the decreased activity of glutathione reductase in cataract lenses is thiol oxidation of the enzyme and an unfolding of enzymes [23].

Among our patients, a significantly higher concentration of total thiol groups was measured in lenses with incipient $(102.5 \pm 25.5 \mu \mathrm{mol} / \mathrm{g})$ compared to lenses with mature $(54.8 \pm 19.7 \mu \mathrm{mol} / \mathrm{g})(P<0.001)$ age-related cataract. During the development of cataract, the amount of thiol groups in the crystalline is being progressively reduced, as a result of "unfolding" macromolecular chains of protein and consequent oxidation of disulfide bonds. This reduction of the concentration of protein-SH groups in the older lenses depends on the availability of GSH and GSH-dependent enzymes.

Membrane protein thiol groups of lens epithelial cells, which are important for the regulation of ion transport, are highly susceptible to oxidative attack, especially when the level of intracellular GSH is decreased. Optimal membrane function of lens epithelial cells depends on the reduced state of protein-SH groups. The loss of membrane-SH groups and consequent increase of membrane permeability, which occurs as a consequence of oxidative damage, are probably involved in the development of cataract. Oxidation of membrane thiol groups of lenses leads to disruption of active transport through the membrane, which is accompanied by intracellular changes. Disturbed active transport leads to reduced levels of vitamin C in the lens. Studies have confirmed that ascorbate levels in human lenses with the development of age-related cataracts are reduced [26], and concentration of dehydrascorbate is increased [11]. Measured concentrations of total vitamin $\mathrm{C}$ and ascorbic acid concentrations in our patients are consistent with these tests. With progression of cataracts, from the incipient to mature, the concentration of total vitamin $\mathrm{C}$ and ascorbic acid is progressively reduced (Table 1), while the amount of dehydroascorbic acid does not change significantly. However, the ratio of DHA/AA is more important for estimating the participation of vitamin $\mathrm{C}$ in antioxidant protection of lenses than the concentration of total vitamin C. In the lenses of our patients, the higher concentration of DHA was measured compared to concentration of AA, regardless of the maturity degree of the cataract.

Accordingly, the concentration ratio of DHA/AA was higher in mature cataracts, where the measured concentration of AA is significantly lower than in the incipient cataract (Table 1). Higher concentration ratio of DHA/AA indicates the presence of oxidative stress. Higher concentration of dehydroascorbate in lenses of our patients can be explained by the inability of its reduction in ascorbic acid due to decreased amount of reduced glutathione, which is measured in the test lenses (Table 1).

It is possible that low level of reduced glutathione in the lens leads to an increase of degradation products of ascorbic acid (dehydroascorbic acid (DHA), 2.3-diketogulonic acid, L-xylosone, and L-threose). Some believe that these 
intermediate potential agents modifications of lens proteins are even more potent than those of glucose [27], and that modification of crystalline lens by these products leads to their aggregation and precipitation [11]. In experimental conditions, exposure of rabbit lenses to dehydroascorbic acid in conditions of suppressed reduction of GSSG by glutathione reductase leads to lens opacification few hours after the experiment started [28].

Experiments on isolated proteins showed that oxidation products of ascorbate can form cross-link with crystalline lens, producing molecules of high molecular weight, which cause light scattering typical for cataract [14]. It is assumed that similar modification of lens proteins occurs in vivo during the development of age-related cataract [29]. However, in balanced physiological condition of prooxidant and antioxidant, there is a small possibility that some oxidation products of ascorbate are to be involved as cataractogenic factors, because of their short half-life and rapid reduction in the presence of reduced glutathione. Decreased reduction of DHA to ascorbic acid and consequent accumulation of DHA in the lens are also contributed with reduced activity of enzymes of dehydroascorbate reductase, due to lower concentration of available reduced glutathione, especially in the nucleus of the lens due to formation of some sort of transport barrier [30]. Modification of lens proteins can accelerate the creation of a barrier between metabolically active cortex and inert nucleus [31], that prevents the diffusion of antioxidant molecules to the nuclear part, so the center of the lens is more exposed to oxidation, which is important for the development of nuclear cataract [32]. This probably causes the decrease of GSH concentration in the nucleus of the lens, so the response to oxidative damage in this part of the lens is reduced [31].

FRAL analysis was used to assess total antioxidant ability of the lens with age-related cataract. This analysis examines ferric-reducing ability of the sample and it is based on ability of antioxidant to reduce $\mathrm{Fe}^{+3}$ to $\mathrm{Fe}^{+2}$. Significantly higher ferric-reducing ability is found in lenses of patient with incipient cataract $(P<0.001)$ compared to lenses with mature cataract (Table 1), then the lenses with posterior subcapsular cataract $(P<0.001)$ are compared to lenses with corticonuclear cataract (Table 2). In lenses of the patients with mature age-related cataract, significantly higher values of FRAL analysis were measured in lenses where the cataract started as posterior subcapsular $(P<0.05)$ than in lenses where the cataract started as corticonuclear (Table 3 ). These results are consistent with the measured concentrations of individual antioxidants in lenses with age-related cataract. In lenses with mature cataract, a smaller amount of reduced glutathione, lower concentration of total thiol groups, and lower concentration of total vitamin $\mathrm{C}$ and ascorbate were measured, compared to lenses of patients with incipient cataract (Table 1). Consequently, the total antioxidant ability of lenses with mature cataract is lower compared to lenses with incipient cataract (Table 1). With the development and the progression of cataract towards total (mature) cataract, comes the consumption and exhaustion of antioxidants, and the activity of antioxidant enzymes is reduced, as a result of changing of structure of enzyme molecules, and/or as a result of decreased synthesis of enzymes, or as a result of reducing the amount of reduced glutathione, which is necessary for the activity of glutathione-dependent enzymes. Significantly lower ferric-reducing ability of lenses in which the nuclear part is affected by cataract changes (Tables 2 and 3 ) shows the higher nucleus sensibility to oxidative damages compared to cortex of the lens, probably because of the location, structure, and physiological inertness in relation to epithelium of cortical parts.

\section{Conclusion}

The concentration of antioxidants decreases in lenses with the progression of cataract towards mature, whereby the lowest total antioxidant activity was detected in cataracts with nuclear component. The highest concentration of dehydroascorbic acid and redox balance of DHA/AA was measured in mature cataracts, which started as cortical nuclear. Timely removal of DHA from the lens is important because of its potential toxicity as an oxidant and/or its degradation products. For the reduction of DHA to AA, it is very important to maintain activities of glutathione/redox cycles in the lens, which prevents the accumulation of DHA and prevents lens clouding. Also, the increase of the current concentration of DHA/AA redox balance can be an indicator of oxidative stress.

\section{References}

[1] H. R. Taylor, S. K. West, F. S. Rosenthal et al., "Effect of ultraviolet radiation on cataract formation," New England Journal of Medicine, vol. 319, no. 22, pp. 1429-1433, 1988.

[2] C. Delcourt, I. Carrière, A. Ponton-Sanchez, A. Lacroux, M. J. Covacho, and L. Papoz, "Light exposure and the risk of cortical, nuclear, and posterior subcapsular cataracts: the Pathologies Oculaires Liees a l'age (POLA) study," Archives of Ophthalmology, vol. 118, no. 3, pp. 385-392, 2000.

[3] R. Kannan, A. Stolz, Q. Ji, P. D. Prasad, and V. Ganapathy, "Vitamin C transport in human lens epithelial cells: evidence for the presence of SVCT2," Experimental Eye Research, vol. 73, no. 2, pp. 159-165, 2001.

[4] D. L. Garland, "Ascorbic acid and the eye," American Journal of Clinical Nutrition, vol. 54, no. 6, pp. 1198S-1202S, 1991.

[5] F. J. Giblin, "Glutathione: a vital lens antioxidant," Journal of Ocular Pharmacology and Therapeutics, vol. 16, no. 2, pp. 121$135,2000$.

[6] M. F. Lou, "Thiol regulation in the lens," Journal of Ocular Pharmacology and Therapeutics, vol. 16, no. 2, pp. 137-148, 2000.

[7] A. Spector, W. Ma, R. R. Wang, Y. Yang, and Y. S. Ho, "The contribution of GSH peroxidase-1, catalase and GSH to the degradation of $\mathrm{H}_{2} \mathrm{O}_{2}$ by the mouse lens," Experimental Eye Research, vol. 64, no. 3, pp. 477-485, 1997.

[8] J. Sedlak and R. H. Lindsay, "Estimation of total, proteinbound, and nonprotein sulfhydryl groups in tissue with Ellman's reagent," Analytical Biochemistry, vol. 25, no. C, pp. 192-205, 1968.

[9] D. B. McCormic, "Vitamins," in Textbook of Clinical Chemistry, N. W. Tietz, Ed., p. 927, WB Saunders Company, Philadelphia, Pa, USA, 1986. 
[10] I. F. F. Benzie and J. J. Strain, "The ferric reducing ability of plasma (FRAP) as a measure of "antioxidant power": the FRAP assay," Analytical Biochemistry, vol. 239, no. 1, pp. 70-76, 1996.

[11] M. Linetsky, E. Shipova, R. Cheng, and B. J. Ortwerth, "Glycation by ascorbic acid oxidation products leads to the aggregation of lens proteins," Biochimica et Biophysica ActaMolecular Basis of Disease, vol. 1782, no. 1, pp. 22-34, 2008.

[12] M. Balaji, K. Sasikala, and T. Ravindran, "Copper levels in human mixed, nuclear brunescence, and posterior subcapsular cataract," British Journal of Ophthalmology, vol. 76, no. 11, pp. 668-669, 1992.

[13] B. Garner, M. J. Davies, and R. J. W. Truscott, "Formation of hydroxyl radicals in the human lens is related to the severity of nuclear cataract," Experimental Eye Research, vol. 70, no. 1, pp. 81-88, 2000.

[14] R. H. Nagaraj and V. M. Monnier, "Protein modification by the degradation products of ascorbate: formation of a novel pyrrole from the Maillard reaction of L-threose with proteins," Biochimica et Biophysica Acta-Protein Structure and Molecular Enzymology, vol. 1253, no. 1, pp. 75-84, 1995.

[15] S. H. Slight, M. S. Feather, and B. J. Ortwerth, "Glycation of lens proteins by the oxidation products of ascorbic acid," Biochimica et Biophysica Acta-Protein Structure and Molecular Enzymology, vol. 1038, no. 3, pp. 367-374, 1990.

[16] S. P. Gartaganis, C. D. Georgakopoulos, N. E. Patsoukis, S. S. Gotsis, V. S. Gartaganis, and C. D. Georgiou, "Glutathione and lipid peroxide changes in pseudoexfoliation syndrome," Current Eye Research, vol. 30, no. 8, pp. 647-651, 2005.

[17] L. Zoric, S. Elek-Vlajic, M. Jovanovic et al., "Oxidative stress intensity in lens and aqueous depending on age-related cataract type and brunescense," European Journal of Ophthalmology, vol. 18, no. 5, pp. 669-674, 2008.

[18] M. A. Babizhayev, "Failure to withstand oxidative stress induced by phospholipid hydroperoxides as a possible cause of the lens opacities in systemic diseases and ageing," Biochimica et Biophysica Acta-Molecular Basis of Disease, vol. 1315, no. 2, pp. 87-99, 1996.

[19] O. Donma, E. Ö. Yorulmaz, H. Pekel, and N. Suyugül, "Blood and lens lipid peroxidation and antioxidant status in normal individuals, senile and diabetic cataractous patients," Current Eye Research, vol. 25, no. 1, pp. 9-16, 2002.

[20] B. Kisic, D. Miric, L. Zoric, I. Dragojevic, and A. Stolic, "Role of lipid peroxidation in pathogenesis of senile cataract," Vojnosanitetski Pregled, vol. 66, no. 5, pp. 371-375, 2009.

[21] M. F. Lou, J. E. Dickerson Jr., W. H. Tung, J. K. Wolfe, and L. T. Chylack Jr., "Correlation of nuclear color and opalescence with protein S-thiolation in human lenses," Experimental Eye Research, vol. 68, no. 5, pp. 547-552, 1999.

[22] M. F. Lou and J. E. Dickerson Jr., "Protein-thiol mixed disulfides in human lens," Experimental Eye Research, vol. 55, no. 6, pp. 889-896, 1992.

[23] H. Yan, J. J. Harding, K. Xing, and M. F. Lou, "Revival of glutathione reductase in human cataractous and clear lens extracts by thioredoxin and thioredoxin reductase, in conjunction with $\alpha$-crystallin or thioltransferase," Current Eye Research, vol. 32, no. 5, pp. 455-463, 2007.

[24] M. D. Linetsky, J. M. W. Hill, V. G. Chemoganskiy, F. Hu, and B. J. Ortwerth, "Studies on the mechanism of the UVA lightdependent loss of glutathione reductase activity in human lenses," Investigative Ophthalmology and Visual Science, vol. 44, no. 9, pp. 3920-3926, 2003.

[25] T. Tabatabaie and R. A. Floyd, "Susceptibility of glutathione peroxidase and glutathione reductase to oxidative damage and the protective effect of spin trapping agents," Archives of Biochemistry and Biophysics, vol. 314, no. 1, pp. 112-119, 1994.

[26] W. Huang, A. Koralewska-Makár, B. Bauer, and B. Åkesson, "Extracellular glutathione peroxidase and ascorbic acid in aqueous humor and serum of patients operated on for cataract," Clinica Chimica Acta, vol. 261, no. 2, pp. 117-130, 1997.

[27] K. W. Lee, G. Simpson, and B. Ortwerth, "A systematic approach to evaluate the modification of lens proteins by glycation-induced crosslinking," Biochimica et Biophysica ActaMolecular Basis of Disease, vol. 1453, no. 1, pp. 141-151, 1999.

[28] H. Sasaki, F. J. Giblin, B. S. Winkler, B. Chakrapani, V. Leverenz, and S. Chu-Chen, "A protective role for glutathionedependent reduction of dehydroascorbic acid in lens epithelium," Investigative Ophthalmology and Visual Science, vol. 36, no. 9, pp. 1804-1817, 1995.

[29] X. Fan, L. W. Reneker, M. E. Obrenovich et al., "Vitamin C mediates chemical aging of lens crystallins by the Maillard reaction in a humanized mouse model," Proceedings of the National Academy of Sciences of the United States of America, vol. 103, no. 45, pp. 16912-16917, 2006.

[30] M. H. J. Sweeney and R. J. W. Truscott, "An impediment to glutathione diffusion in older normal human lenses: a possible precondition for nuclear cataract," Experimental Eye Research, vol. 67, no. 5, pp. 587-595, 1998.

[31] J. A. Vinson, "Oxidative stress in cataracts," Pathophysiology, vol. 13, no. 3, pp. 151-162, 2006.

[32] R. J. W. Truscott, "Age-related nuclear cataract-oxidation is the key," Experimental Eye Research, vol. 80, no. 5, pp. 709$725,2005$. 


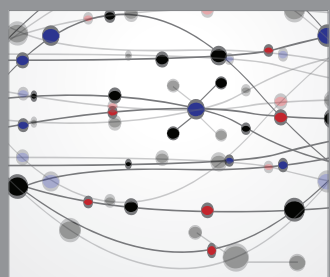

The Scientific World Journal
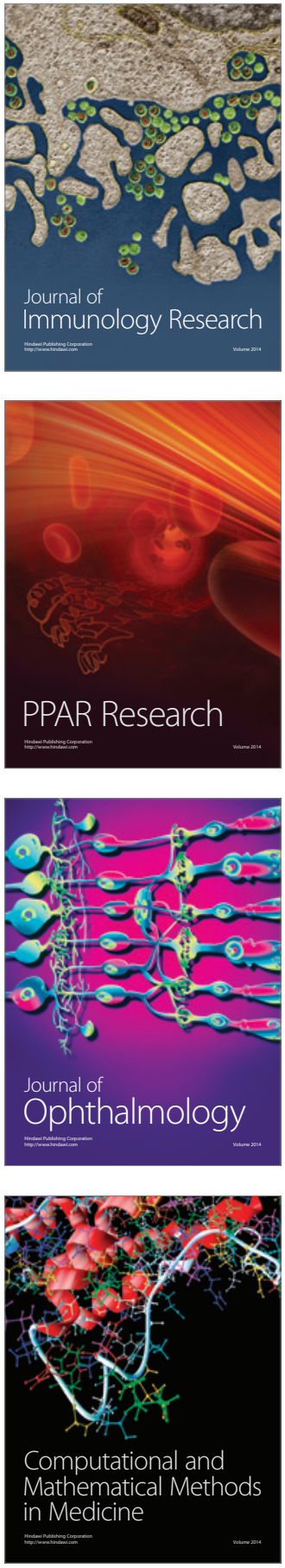

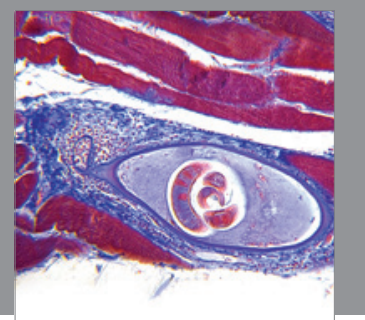

Gastroenterology

Research and Practice
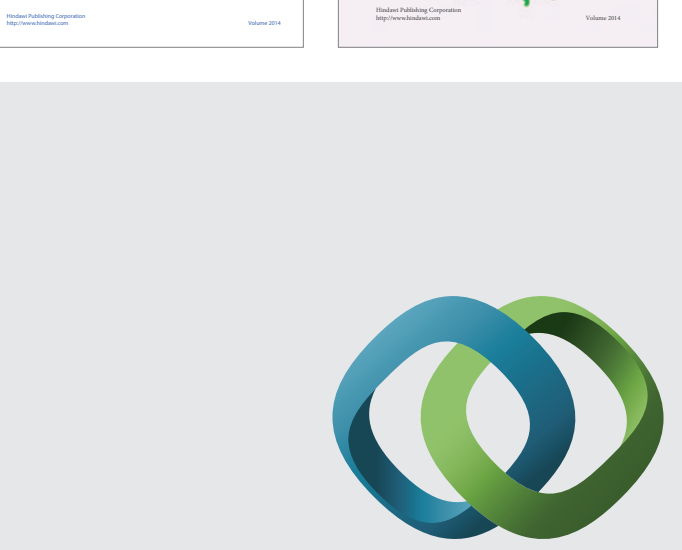

\section{Hindawi}

Submit your manuscripts at

http://www.hindawi.com
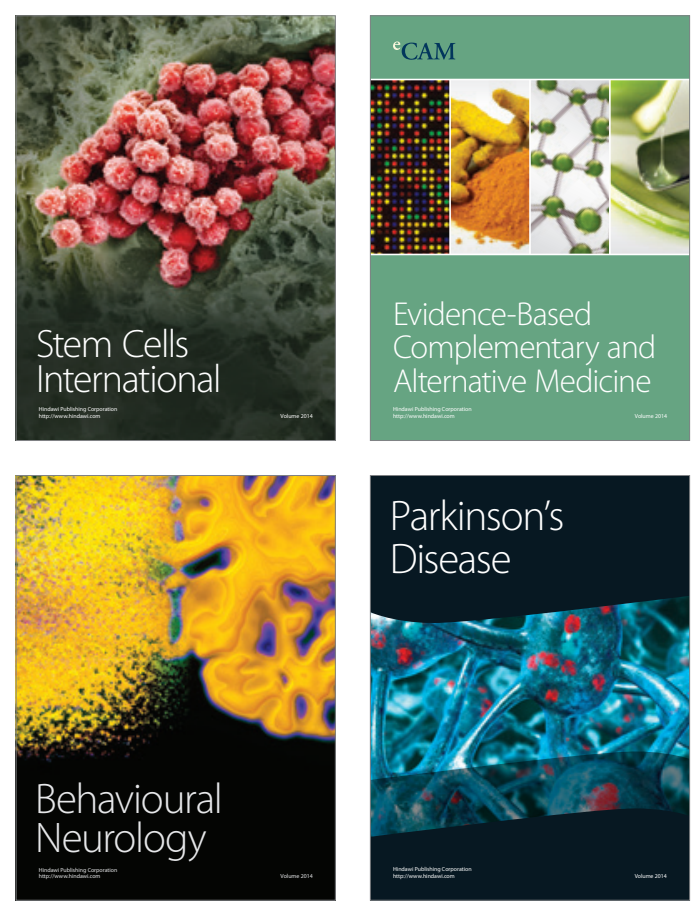

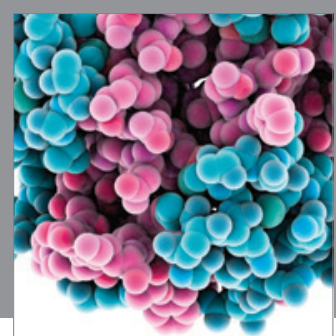

Journal of
Diabetes Research

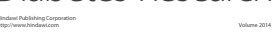

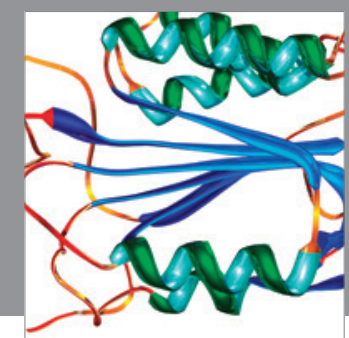

Disease Markers
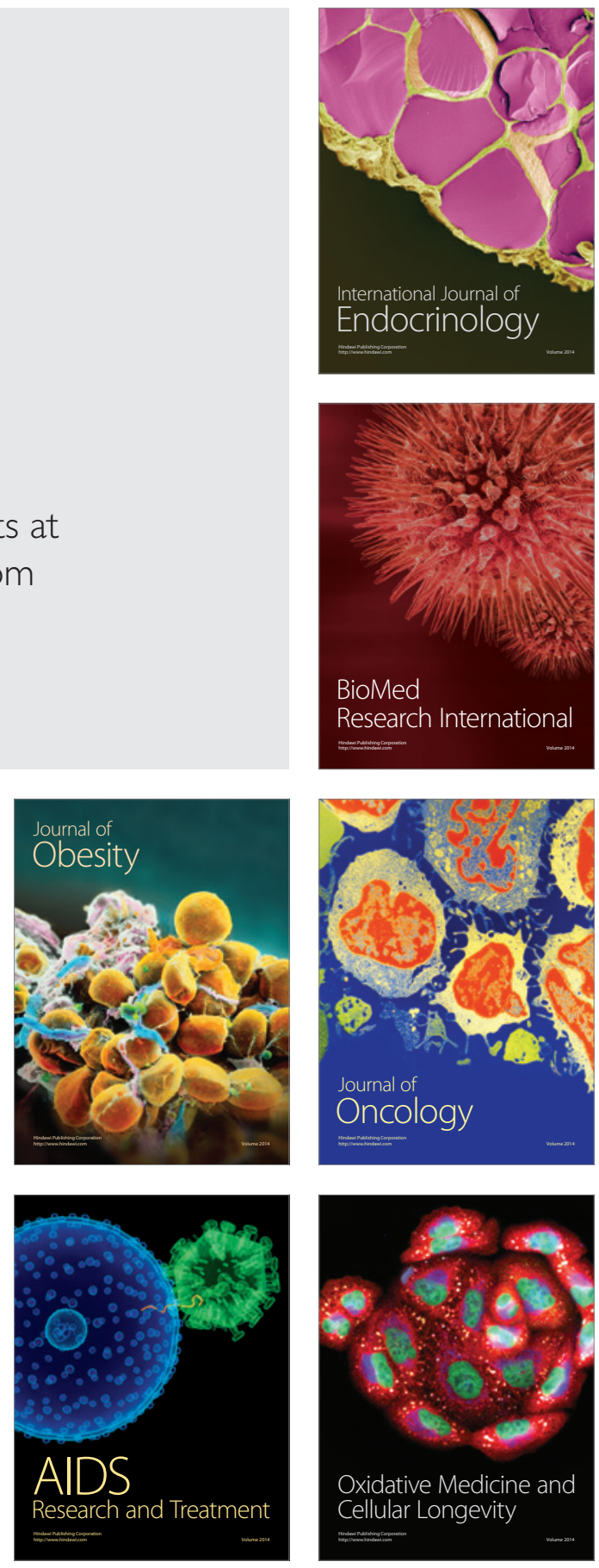